\title{
Proposta metodológica para o cálculo de espaçamento entre sulcos de mulching vertical ${ }^{1}$
}

\author{
Rafael Carlos dos Santos ${ }^{2}$, Caetano Marciano de Souza ${ }^{3}$, Marcos Júnio Rezende ${ }^{4}$, João Luiz Lani ${ }^{5}$, \\ Paulo Roberto Cecon ${ }^{6}$, Marcos Antônio Gomes ${ }^{7}$
}

\begin{abstract}
RESUMO
O mulching vertical é uma prática mecânica para contenção do escoamento superficial que, apesar de mostrar-se promissora, ainda se encontra em fase de validação. Assim, este estudo teve como objetivo propor e testar uma metodologia para o cálculo do espaçamento entre sulcos de mulching vertical, quanto à eficiência na redução das perdas de água, solo e nutrientes por escoamento superficial, em condições de campo. A pesquisa foi desenvolvida entre outubro de 2009 e março de 2010, durante o ciclo da cultura do milho (Zea mays), em uma área de semeadura direta consolidada. Utilizou-se o delineamento em blocos casualizados, com quatro repetições e seis tratamentos constituídos de sulcos de mulching vertical, construídos perpendicularmente ao declive, distribuídos em diferentes distâncias. Nas amostras de escoamento, foram analisados os seguintes atributos: volume de água perdido, massa de solo no sedimento e nutrientes no sedimento e na água de escoamento superficial. Não foram constatadas diferenças significativas para o efeito de tratamentos nas perdas de solo. De forma geral, os tratamentos com 0 e 5,4 m entre sulcos foram os mais eficientes em conter as perdas de água e de nutrientes (na água e no sedimento). Pela metodologia proposta e nas condições avaliadas, o mulching vertical não se mostrou eficiente em conter as perdas de água, solo e nutrientes por escoamento superficial.
\end{abstract}

Palavras-chave: escoamento superficial, sedimento, valetadeira rotativa.

\begin{abstract}
\section{Proposed methodology for determination of vertical mulching spacing}

Vertical mulching is a method for containment of runoff that despite promising is still being validated. Thus, this study aimed to propose and test a methodology for calculating the row spacing of vertical mulching, and efficiency in reducing losses of water, soil and nutrient by runoff in the field. The experiment was conducted from october 2009 to march 2010 during the corn (Zea mays) crop cycle in a consolidated no-till area. We used a randomized block design with four replications and six treatments consisting of vertical mulching furrows opened perpendicularly to the slope, distributed at different distances. In runoff samples, the following attributes were analyzed: volume of water lost, soil mass in the sediment, nutrients in the sediment and water runoff. There were no significant differences for the effect of
\end{abstract}

\footnotetext{
Recebido para publicação em 09/05/2012 e aprovado em 24/04/2013.

${ }^{1}$ Parte da dissertação de Mestrado do primeiro autor.

${ }^{2}$ Engenheiro-Agrônomo, Mestre. Departamento de Fitotecnia, Campus Viçosa, Universidade Federal de Viçosa, Avenida Peter Henry Rolfs, s/n, 36570-000, Viçosa, Minas Gerais, Brasil. rafael.carlos@ufv.br (autor para correspondência).

${ }^{3}$ Engenheiro-Agrônomo, Doutor. Departamento de Fitotecnia, Campus Viçosa, Universidade Federal de Viçosa, Avenida Peter Henry Rolfs, s/n, 36570-000, Viçosa, Minas Gerais, Brasil.cmsouza@ufv.br

${ }^{4}$ Graduando em Engenharia Florestal. Departamento de Engenharia Florestal, Universidade Federal de Viçosa, Avenida Peter Henry Rolfs, s/n, 36570-000, Viçosa, Minas Gerais, Brasil. marcos.rezende@ufv.br

${ }^{5}$ Engenheiro-Agrônomo, Doutor. Departamento de Solos, Universidade Federal de Viçosa, Campus Viçosa, Avenida Peter Henry Rolfs, s/n, 36570-000, Viçosa, Minas Gerais, Brasil. lani@ufv.br

${ }^{6}$ Engenheiro-Agrônomo, Doutor. Departamento de Estatistica, Universidade Federal de Viçosa, Campus Viçosa, Avenida Peter Henry Rolfs, s/n, 36570-000, Viçosa, Minas Gerais, Brasil. cecon@ufv.br

${ }^{7}$ Engenheiro Florestal, Doutor. EPAMlG - Empresa de Pesquisa Agropecuária de Minas Gerais, Campus Viçosa, Vila Gianetti, Casa Q, 36570-000, Viçosa, Minas Gerais, Brasil. marcos.heman@hotrnail.com
}

Rev. Ceres, Viçosa, v. 60, n.4, p. 552-562, jul/ago, 2013 
treatments on soil losses. Generally, the treatment with 0 and 5.4 meters between furrows were more efficient in holding the loss of water and nutrients (in water and sediment). For the proposed method and evaluated conditions, the vertical mulching was not efficient in containing losses of water, soil and nutrients in runoff.

Key words: runoff, sediment, rotary trencher.

\section{INTRODUÇÃO}

O preparo do solo é uma etapa fundamental para realização do cultivo nas áreas agrícolas e pode ser feito em sistemas convencional, mínimo ou direto (Herbes, 2003; Dalla Costa, 2004). No sistema convencional de preparo, a aração e gradagem, ao promoverem a movimentação e a desagregação do solo, potencializam o processo de mineralização da matéria orgânica e reduzem a cobertura proporcionada pelos resíduos culturais. Esses resíduos atuam reduzindo o selamento superficial e a velocidade do escoamento superficial e, consequentemente, a força erosiva da enxurrada (Cogo et al., 2003).

O sistema de preparo convencional pode acarretar a compactação da subsuperfície do solo, promovida pelos implementos utilizados nas atividades de preparo e cultivo, reduzindo a infiltração da água, resultando, portanto, em aumento do escoamento superficial e, consequentemente, em erosão (Bertol et al., 1997).

A semeadura direta é um sistema de cultivo que tem como objetivos manter a cobertura permanente do solo, reduzir a movimentação, a desestruturação e a erosão causada pela água durante o período das chuvas (Garcia \& Rigles, 2008). A eficiência da semeadura direta, na redução das perdas de solo por erosão hídrica, observada pelos agricultores, e o aumento na operacionalidade das máquinas agrícolas, fizeram com que as práticas mecânicas de contenção das perdas de água e solo, como, por exemplo, os terraços, fossem abandonadas (Garcia \& Rigles, 2008).

Entretanto, diversos autores, como Cogo (1981), Bertol et al. (1989), Alves et al. (1995) e Cogo et al. (2003) afirmam que, de modo geral, as perdas de água têm sido muito variadas e menos influenciadas pela cobertura morta na superfície do solo, quando comparadas com as perdas de solo, podendo, em alguns casos ser semelhantes ou até superiores a estas.

Por essas razões, novas práticas conservacionistas, como o mulching vertical, vêm sendo testadas e aplicadas de forma conjunta, com vistas a aumentar a infiltração de água e, consequentemente, reduzir a erosão. Estudos recentemente realizados sobre a técnica (Herbes, 2003; Dalla Costa, 2004; Garcia \& Rigles, 2008), em diferentes condições de uso, descrevem-na como eficiente e promissora, relatando que, em muitos casos, os terraços estão sendo substituídos pelo mulching vertical, que apresenta maior praticidade e facilidade de construção, menor movimentação de solo e menor custo, além de não dificultar o trânsito de máquinas nas áreas onde são implantados.

Segundo Klein et al. (2000), o estudo dessa técnica é justificável, por sua operacionalidade, facilidade de construção e economia, advinda da redução das perdas de calcário e fertilizantes e, também, pela redução da poluição dos recursos hídricos.

Todavia, de acordo com Denardin et al. (2005), em decorrência do atual estágio de estudo, ainda incipiente, a indicação do mulching vertical está sendo limitada a solos bem drenados e a áreas específicas de lavouras manejadas sob sistema plantio direto, com declives propensos à concentração de enxurrada e, ou, com problemas evidentes de erosão. Outras limitações à utilização da referida técnica são o requerimento de grande quantidade de resíduos vegetais e a necessidade de preenchimento manual dos sulcos (Anschütz et al., 2005), tendo em vista ainda não terem sido desenvolvidos equipamentos específicos para essa finalidade.

Apesar dos resultados promissores supracitados e dos muitos benefícios apontados, a técnica ainda se encontra em fase de validação, sendo que a metodologia de cálculo do espaçamento entre os sulcos ainda não está claramente definida para a sua recomendação e aplicação. Diante disso, este estudo teve como objetivo propor e testar uma metodologia para o cálculo do espaçamento entre sulcos de mulching vertical, quanto à eficiência em conter as perdas de água, solo e nutrientes por escoamento superficial em condições de campo, tomando por base os índices considerados para o cálculo de espaçamento entre terraços, com as suas devidas adaptações.

\section{MATERIAL E MÉTODOS}

O trabalho foi realizado na estação experimental do Departamento de Fitotecnia da Universidade Federal de Viçosa, em Coimbra, Minas Gerais. A área experimental encontra-se no terço inferior de uma encosta com declividade média de $10 \%$ e o solo foi classificado como 
Argissolo Vermelho-Amarelo distrófico, fase Floresta Tropical Subperenifólia, argiloso/argiloso, relevo suave ondulado, caulinítico (PVAd) (Embrapa, 2006). O clima é o tropical de altitude (Cwb, segundo Köppen), com precipitação média de 1.300 a 1.400 mm (concentrada nos meses de outubro a março) e temperatura média anual de $19{ }^{\circ} \mathrm{C}$.

$\mathrm{O}$ experimento foi instalado em área de semeadura direta consolidada, estabelecida há mais de vinte anos, sendo constituído por seis tratamentos e quatro blocos casualizados. Os tratamentos adotados foram constituídos de sulcos de mulching vertical em diferentes distâncias, dispostos em sentido transversal ao declive, totalizando 24 parcelas experimentais (Figura 1).

\section{A. Cálculo das distâncias entre sulcos de mulching vertical}

As diferentes distâncias entre sulcos, utilizadas para distribuição da técnica em campo, foram calculadas, tomando-se por base o princípio adotado para dimensionamento de terraços de infiltração. Neste caso, o espaçamento entre um terraço e outro, considerando-se o sentido do declive, é dimensionado, visando a receber e infiltrar o volume de água, proveniente do escoamento da área limitada pelo terraço que foi construído na parte superior do terreno. Para a realização dos cálculos, foram considerados os seguintes parâmetros: volume útil do sulco, área útil da parcela e volume de água a ser infiltrado de um dado volume máximo de precipitação.

$\mathrm{O}$ volume útil do sulco foi calculado pela diferença entre o volume total (Vt) e o volume da palha de preenchimento (Vp), pela seguinte fórmula Equação (1):

$$
\mathbf{V t}=\mathbf{r} \mathbf{L} \mathbf{C}
$$

em que: $\mathrm{Vt}=$ Volume total do sulco $\left(\mathrm{m}^{3}\right) ; \mathrm{r}=$ Raio do disco de corte da valetadeira, representando a profundidade do sulco $(0,4 \mathrm{~m}) ; \mathrm{L}=$ Largura do disco de corte e, consequentemente, do sulco $(0,13 \mathrm{~m})$; e $\mathrm{C}=$ Comprimento do sulco em cada parcela $(2 \mathrm{~m})$.

$\mathrm{O}$ volume total do sulco foi de $0,104 \mathrm{~m}^{3}$ por parcela. $\mathrm{O}$ volume ocupado pela palha de trigo foi estimado em $37 \%$ e, a partir deste, encontrou-se o volume útil do sulco, de $0,06552 \mathrm{~m}^{3}$. A área de cada parcela foi de $16 \mathrm{~m}^{2}$, sendo $2 \mathrm{~m}$ de largura x $8 \mathrm{~m}$ de comprimento (Figura 1). Após a determinação desses dados, foi calculada a vazão máxima para cada parcela, pela equação de Manning (Pires \& Souza, 2006).

Para este estudo, o coeficiente de escoamento utilizado foi de 0,54 , considerando-se o solo como de textura argilosa; o tipo de cobertura do solo como cultura perene, uma vez que a literatura não apresenta distinção entre o sistema de preparo do solo (semeadura direta, para este caso) onde a cobertura do solo é mantida; e a topografia como ondulada, com declividade média de $10 \%$. Considerando-se que, no local onde foi conduzido o experimento, a precipitação média anual é de 1.300 a 1.400 mm, concentrada, principalmente, nos meses de outubro a março, adotou-se um valor de intensidade máxima de chuva de 100 $\mathrm{mm} \mathrm{h}^{-1}$, com uma frequência de 25 anos, obtendo-se um tempo de concentração de 40 minutos.

Aplicando-se os valores encontrados à equação de Manning, encontrou-se a vazão de $0,00024 \mathrm{~m}^{3} \mathrm{~s}^{-1}$, e, a partir dessa vazão, encontrou-se o volume de $0,576 \mathrm{~m}^{3} \mathrm{de}$



Figura 1. Esquema representativo dos tratamentos em campo.

Rev. Ceres, Viçosa, v. 60, n.4, p. 552-562, jul/ago, 2013 
enxurrada, produzido durante uma chuva dessa intensidade, pela seguinte Equação (2):

$$
\mathbf{V t}=\mathbf{Q} \mathbf{T c}
$$

em que: $\mathrm{Vt}=$ Volume total de enxurrada produzida durante a chuva; $\mathrm{Q}$ = vazão do escoamento superficial $\left(\mathrm{m}^{3} \mathrm{~s}^{-1}\right)$ e Tc $=$ Tempo de concentração $(\mathrm{s})$.

A partir dos dados de volume total de enxurrada produzida por parcela e do volume útil de cada sulco, calculou-se o número de sulcos (Ns $=8,79)$ que seriam necessários, em cada parcela, para receber o volume de enxurrada produzido (Equação 3):

$$
\mathrm{Ns}=\mathrm{Vt} \mathrm{Vu}^{-1}
$$

em que: Ns = Número de sulcos de mulching verticais por parcela; $\mathrm{Vt}=$ Volume total de enxurrada $\left(\mathrm{m}^{3}\right)$ produzida durante a chuva e $\mathrm{Vu}=$ Volume útil de cada sulco $\left(\mathrm{m}^{3}\right)$.

Finalmente, os espaçamentos entre os sulcos de mulching vertical em campo foram calculados a partir da seguinte Equação (4):

$$
\mathrm{EMV}=\mathrm{C} \mathrm{Ns}^{-1}
$$

em que: $\mathrm{EMV}=$ Espaçamento entre sulcos de mulching vertical $(\mathrm{m}) ; \mathrm{C}=$ Comprimento da parcela $(\mathrm{m})$ e Ns = Número de sulcos de mulching vertical por parcela.

Para facilitar a aplicação no campo, a distância calculada de 0,91 $\mathrm{m}$ foi arredondada para 0,9 m. Depois de calculada a distância entre sulcos, foram estabelecidos múltiplos, compreendidos entre zero e oito, constituindo os tratamentos em campo, representados na Figura 1.

\section{B. Instalação dos tratamentos no campo}

As parcelas foram delimitadas em outubro de 2009, utilizando-se uma valetadeira rotativa, desenvolvida para drenagem em solos de várzea. Os sulcos foram abertos em sentido transversal ao declive, com dimensões de $2 \mathrm{~m}$ x $0,13 \mathrm{~m}$ x $0,4 \mathrm{~m}$ correspondentes a comprimento, largura e profundidade, respectivamente. $\mathrm{O}$ solo proveniente da operação foi redistribuído dentro das parcelas, permanecendo sobre a superfície. Após a abertura, os sulcos foram preenchidos manualmente com palha de trigo, que foi compactada com vista a proporcionar estabilidade às paredes dos sulcos, evitando desmoronamentos.

As parcelas experimentais foram delimitadas lateralmente com chapas de madeira enterradas no solo a $0,1 \mathrm{~m}$ de profundidade, para evitar que a água de uma parcela escoasse para a parcela vizinha. Ao final de cada parcela, foram instalados coletores de escoamento e, dentro de cada bloco, foram colocados coletores de precipitação (pluviômetros), num total de cinco coletores por bloco (Figura 1).
O experimento foi conduzido tendo o milho, Cultivar Dekalb (DKB 747), como cultura teste, semeado no início de novembro de 2009, com uma população de 55 mil plantas por hectare. Anteriormente à semeadura, foi feita a dessecação da vegetação nas parcelas experimentais, utilizando-se a mistura dos herbicidas Glyphosate e 2,4-D. Durante a condução da cultura, o controle das plantas daninhas foi feito, utilizando-se os herbicidas Atrazine e Nicossulfuron. Na adubação de semeadura, foram utilizados $400 \mathrm{~kg} \mathrm{ha}^{-1}$ da formulação 8-28-16 (NPK).

Anteriormente à implantação dos tratamentos, foram coletadas amostras no perfil do solo, em diferentes profundidades, para determinação da condutividade hidráulica em meio saturado $\left(\mathrm{k}_{0}\right)$, da densidade do solo, da porosidade e dos atributos texturais. Durante a condução do experimento, foram quantificadas as precipitações pluviométricas e o escoamento proveniente de cada parcela, sendo que os dados de máxima intensidade de precipitação foram obtidos junto ao banco de dados meteorológicos do Departamento de Engenharia Agrícola da UFV (Tabela 1).

No escoamento superficial foi estimada a quantidade de água e de solo perdidos, a concentração, na água e no solo, dos seguintes atributos: fósforo, potássio, cálcio, magnésio e matéria orgânica, segundo Tedesco et al. (1995).

O volume total de água perdido por escoamento nas parcelas (Figura 2) foi estimado pela relação entre o volume perdido nas precipitações de $50 \mathrm{~mm}$ e o volume total precipitado, para o período 2009/10, correspondente a 931 $\mathrm{mm}$, determinado por meio de medições em campo. Partindo-se desse mesmo princípio, as quantidades totais de solo, perdidas por escoamento superficial, no período 2009/10 (Figura 3), foram estimadas com base no volume total de água escoado nas parcelas. As quantidades totais de nutrientes perdidos por escoamento superficial (Tabela 2) foram estimadas, em relação às quantidades totais de água e de solo perdidas, por hectare, no período 2009/10.

Os valores obtidos para a perda de água e de solo e o teor de nutrientes na água e no solo, provenientes do escoamento, foram submetidos à análise de variância, utilizando-se o programa estatístico SAEG (2007). Na comparação entre médias, foi utilizado o teste de Tukey a 5\% de probabilidade de erro.

\section{RESULTADOS E DISCUSSÃO}

\section{A. Perdas de água e nutrientes por escoamento superficial}

Ao analisar os valores de perda de água (Figura 4), foi possível verificar que o tratamento com 0,9 m entre sulcos diferiu significativamente dos demais tratamentos, exceto 
do tratamento com 7,2 $\mathrm{m}$, apresentando maiores perdas de água $\left(8,47 \mathrm{~m}^{3} \mathrm{ha}^{-1}\right)$ por escoamento superficial.

Os tratamentos com 0 e 3,6 m entre sulcos apresentaram os menores valores de perda de água, diferindo significativamente dos tratamentos com 0,9 e 7,2 m. Os maiores valores de perda de água por escoamento superficial, na parcela com 0,9 m entre sulcos, devem-se possivelmente ao fato de, nesse espaçamento, mesmo os sulcos permanecendo mais próximos na parcela, a movimentação excessiva do solo pode ter provocado um efeito inverso ao esperado, uma vez que a terra mantida sobre as parcelas pode ter causado selamento na superfície do solo, entupindo os macroporos de drenagem, reduzindo a infiltração da água e, consequentemente, potencializando as perdas por escoamento superficial.

Morin \& Van Winkel (1996) citam que a dispersão físico-química das argilas causa a formação do selamento superficial e, consequentemente, a redução da taxa de infiltração. Herbes (2003) ressalta que o selamento superficial impede a infiltração da água, mesmo quando as camadas inferiores do solo ainda têm capacidade de absorção.

Tabela 1. Valores de precipitação pluvial total $(\mathrm{mm})$ e de intensidade máxima de precipitação $\left(\mathrm{mm} \mathrm{h}^{-1}\right)$ para os meses de outubro a março no período de 2004/05 a 2009/10 na região de Coimbra, MG

\begin{tabular}{|c|c|c|c|c|c|c|c|}
\hline \multirow{3}{*}{ Período } & \multicolumn{6}{|c|}{ Meses } & \multirow{2}{*}{ Total } \\
\hline & Out. & Nov. & Dez. & Jan. & Fev. & Mar. & \\
\hline & \multicolumn{6}{|c|}{ Precipitação pluvial (mm) } & $(\mathbf{m m})$ \\
\hline $2004 / 05$ & 65,90 & 186,40 & 130,80 & 196,00 & 252,60 & 317,70 & 1149,40 \\
\hline $2005 / 06$ & 58,10 & 103,90 & 304,50 & 179,90 & 92,60 & 183,50 & 922,50 \\
\hline $2006 / 07$ & 197,60 & 201,50 & 187,60 & 433,60 & 88,10 & 45,50 & 1153,90 \\
\hline $2007 / 08$ & 45,70 & 65,60 & 179,20 & 236,80 & 103,20 & 238,40 & 868,90 \\
\hline 2008/09 & 41,80 & 223,00 & 593,20 & 237,60 & 170,20 & 273,40 & 1539,20 \\
\hline $2009 / 10^{*}$ & 117,90 & 137,50 & 393,50 & 57,30 & 45,50 & 184,80 & 936,50 \\
\hline Média & 87,83 & 152,98 & 298,13 & 223,53 & 125,37 & 207,22 & 1095,07 \\
\hline \multirow[t]{2}{*}{$s}$. & 60,35 & 61,09 & 173,53 & 122,31 & 74,2 & 94,63 & 227,21 \\
\hline & \multicolumn{6}{|c|}{ Máxima intensidade de precipitação $\left(\mathrm{mm} \mathrm{h}^{-1}\right)$} & Média \\
\hline $2004 / 05$ & 20,00 & 40,00 & 40,00 & 40,00 & 40,00 & 40,00 & 36,67 \\
\hline $2005 / 06$ & 20,00 & 20,00 & 40,00 & 40,00 & 40,00 & 40,00 & 33,33 \\
\hline $2006 / 07$ & 40,00 & 40,00 & 40,00 & 40,00 & 40,00 & 40,00 & 40,00 \\
\hline 2007/08 & 40,00 & 40,00 & 40,00 & 40,00 & 40,00 & 40,00 & 40,00 \\
\hline 2008/09 & 40,00 & 40,00 & 40,00 & 40,00 & 40,00 & 20,00 & 36,67 \\
\hline $2009 / 10$ & 10,00 & 10,00 & 20,00 & 10,00 & 8,00 & 10,00 & 11,33 \\
\hline Média & 28,33 & 31,67 & 36,67 & 35,00 & 34,67 & 31,67 & 33,00 \\
\hline$s$ & 13,29 & 13,29 & 8,16 & 12,25 & 13,06 & 13,29 & 10,90 \\
\hline
\end{tabular}

$\mathrm{s}=$ desvio padrão

*Dados de medições realizadas no espaço experimental

Fonte: Departamento de Engenharia Agrícola/UFV (2010).

Médias seguidas por mesma letra não diferem entre si, a 5\% de significância, pelo teste Tukey.

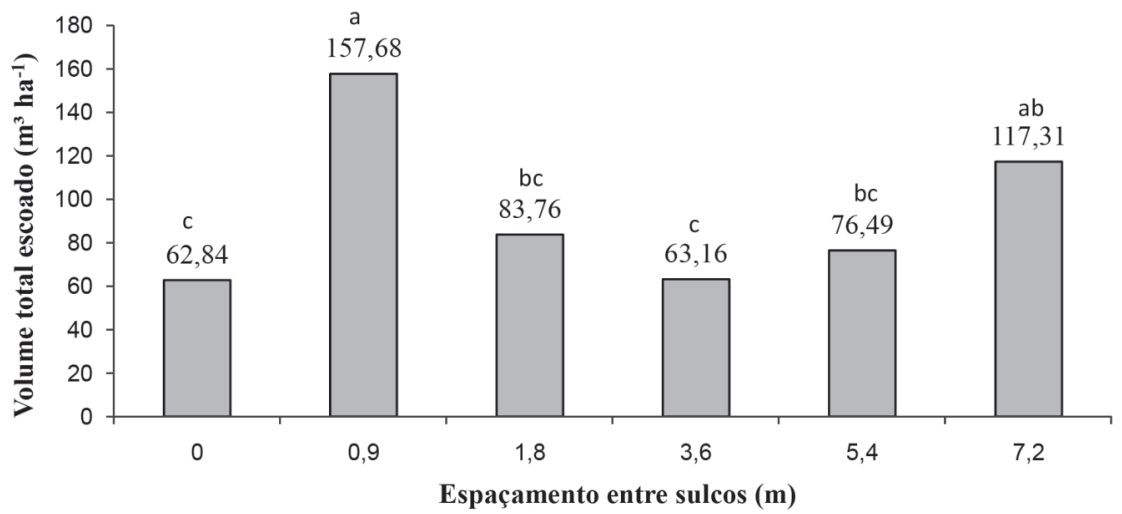

Médias seguidas por mesma letra não diferem entre si, a 5\% de significância, pelo teste Tukey.

Figura 2. Perdas totais de água por escoamento superficial no período 2009/10 em sistema de semeadura direta com sulcos de mulching vertical em diferentes espaçamentos nas parcelas.

Rev. Ceres, Viçosa, v. 60, n.4, p. 552-562, jul/ago, 2013 
Os atributos físicos do solo (Tabela 3) evidenciam a existência de uma camada de maior densidade $\left(1,41 \mathrm{~g} \mathrm{~cm}^{-3}\right)$ e menor porosidade $\left(0,43 \mathrm{~cm}^{3} \mathrm{~cm}^{-3}\right)$ na profundidade de 20-25 cm em relação às camadas adjacentes, indicando maior compactação nessa faixa do perfil. De acordo com Reichert et al. (2007), a presença de compactação ocasiona redução da taxa de infiltração de água e da condutividade hidráulica do solo saturado, aumentando o escoamento superficial. Este fato pode ser constatado pela redução de 2,5 e 2 vezes na condutividade hidráulica em meio saturado, quando comparado com a das camadas superior $(5-10 \mathrm{~cm})$ e inferior $(40-45 \mathrm{~cm})$, respectivamente.

O mulching vertical, por sua vez, promove o rompimento desta camada compactada, o que a princípio possibilitaria maior infiltração da água. Entretanto, nas parce- las com 0,9 m entre sulcos, além da maior movimentação de solo, anteriormente citada, outro fator relevante, que deve ser levado em consideração, é o maior teor de argila dispersa em água nas camadas superiores do solo (até 20 cm) (Tabela 3). Esta, além de dificultar a formação de macroagregados estáveis, no solo, quando sobre a superfície, afeta a rugosidade do solo, podendo ser translocada per descendum, causando entupimento de poros maiores e, consequentemente, o selamento superficial (Schaefer et al., 2002).

Nas parcelas onde foram utilizados 7,2 m entre sulcos, as maiores quantidades perdidas de água, em relação aos tratamentos com 0 e 3,6 m, devem-se possivelmente ao fato de nesse espaçamento o único sulco de mulching vertical não ter sido capaz de comportar e infiltrar toda a

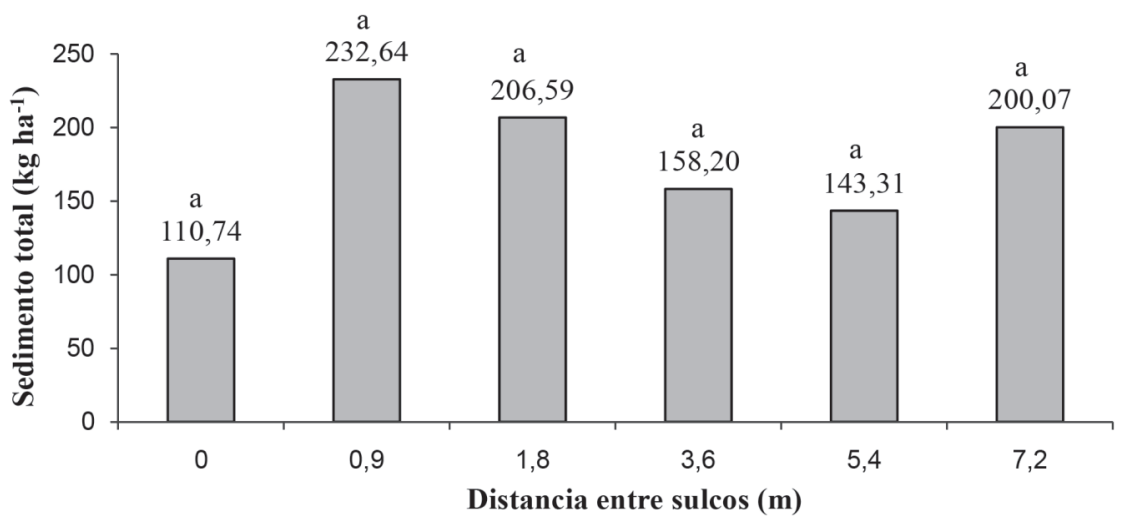

Médias seguidas por mesma letra não diferem entre si, a 5\% de significância, pelo teste Tukey.

Figura 3. Perdas totais de solo por escoamento superficial no período 2009/10 em sistema de semeadura direta com sulcos de mulching vertical em diferentes espaçamentos nas parcelas.

Tabela 2. Quantidades totais de nutrientes e matéria orgânica (MO), perdidos na água e no sedimento provenientes do escoamento superficial em sistema de semeadura direta com Mulching Vertical no perído 2009/10

\begin{tabular}{|c|c|c|c|c|c|}
\hline Tratamento & MO & $P$ & $\boldsymbol{K}^{+}$ & $\mathrm{Ca}^{2+}$ & $\mathrm{Mg}^{2+}$ \\
\hline Espaço entre sulcos (m) & \multicolumn{5}{|c|}{$\mathrm{kg} \mathrm{ha}^{-1}$} \\
\hline & \multicolumn{5}{|c|}{ Solução } \\
\hline 0 (0 EVMV) & $0,195 \mathrm{c}$ & $0,003 \mathrm{~b}$ & $0,340 \mathrm{~b}$ & $0,363 \mathrm{e}$ & $0,050 \mathrm{c}$ \\
\hline 0,9 (1 EVMV) & $1,05 \mathrm{a}$ & $0,017 \mathrm{a}$ & $1,233 \mathrm{a}$ & $0,887 \mathrm{a}$ & $0,127 \mathrm{a}$ \\
\hline 1,8 (2 EVMV) & $0,333 \mathrm{bc}$ & $0,010 \mathrm{ab}$ & $0,533 \mathrm{~b}$ & $0,475 \mathrm{c}$ & $0,060 \mathrm{c}$ \\
\hline 3,6 (4 EVMV) & $0,203 \mathrm{c}$ & $0,008 \mathrm{ab}$ & $0,410 \mathrm{~b}$ & $0,350 \mathrm{e}$ & $0,050 \mathrm{c}$ \\
\hline 5,4 (6 EVMV) & $0,448 \mathrm{bc}$ & $0,013 \mathrm{ab}$ & $0,453 \mathrm{~b}$ & $0,430 \mathrm{~d}$ & $0,060 \mathrm{c}$ \\
\hline 7,2 (8 EVMV) & $0,905 \mathrm{ab}$ & $0,013 \mathrm{ab}$ & $0,860 \mathrm{ab}$ & $0,663 \mathrm{~b}$ & $0,093 \mathrm{~b}$ \\
\hline \multirow[t]{2}{*}{$\mathrm{CV}(\%)$} & 49,74 & 53,31 & 40,16 & 3,10 & 10,85 \\
\hline & \multicolumn{5}{|c|}{ Sedimento } \\
\hline 0 (0 EVMV) & $3,84 \mathrm{~b}$ & $0,002 \mathrm{~b}$ & $0,010 \mathrm{c}$ & $0,041 \mathrm{a}$ & 0,007 a \\
\hline 0,9 (1 EVMV) & $6,58 \mathrm{a}$ & $0,003 \mathrm{a}$ & $0,021 \mathrm{a}$ & $0,058 \mathrm{a}$ & $0,011 \mathrm{a}$ \\
\hline 1,8 (2 EVMV) & $6,40 \mathrm{a}$ & $0,004 \mathrm{a}$ & $0,018 \mathrm{ab}$ & $0,058 \mathrm{a}$ & $0,012 \mathrm{a}$ \\
\hline 3,6 (4 EVMV) & $4,95 \mathrm{ab}$ & $0,003 \mathrm{ab}$ & $0,013 \mathrm{bc}$ & $0,057 \mathrm{a}$ & $0,010 \mathrm{a}$ \\
\hline 5,4 (6 EVMV) & $6,11 \mathrm{ab}$ & $0,003 \mathrm{a}$ & $0,013 \mathrm{bc}$ & $0,055 \mathrm{a}$ & $0,011 \mathrm{a}$ \\
\hline 7,2 (8 EVMV) & $5,75 \mathrm{ab}$ & $0,003 \mathrm{ab}$ & $0,018 \mathrm{ab}$ & $0,059 \mathrm{a}$ & $0,008 \mathrm{a}$ \\
\hline $\mathrm{CV}(\%)$ & 15,09 & 15,78 & 11,44 & 18,19 & 17,62 \\
\hline
\end{tabular}

Médias seguidas de mesma letra na coluna não diferem entre si, pelo teste $\mathrm{F}$, a $5 \%$ de probabilidade. 
água proveniente da parcela. Além disso, pode-se constatar que esse tratamento apresentou resultado inferior ao da parcela testemunha, sem sulcos de mulching vertical, indicando uma redução, nessa parcela, do efeito da cobertura morta no aumento da infiltração de água no solo.

Este efeito deve-se, provavelmente, ao fato de que o trânsito de máquinas durante a abertura dos sulcos, promoveu a compactação do solo, resultante da operação, o qual foi distribuído sobre os resíduos vegetais, reduzindo a rugosidade superficial do solo e a eficiência desses resíduos em conter o escoamento superficial. Segundo Castro et al. (2006), a cobertura morta é fundamental na dissipação da energia cinética das gotas da chuva, impedindo seu impacto direto na superfície do solo, enquanto a rugosidade é importante na retenção e na infiltração superficiais de água, na diminuição da velocidade e do volume da enxurrada. Cogo (1981) argumenta que o trânsito intensivo de máquinas reduz a cobertura superficial por resíduos culturais, dada a sua incorporação parcial ou total no solo.

Esses resultados evidenciaram que, nas condições avaliadas, tanto em espaçamentos reduzidos $(0,9 \mathrm{~m})$, quanto em espaçamentos maiores (7,2 m), o mulching vertical mostrou-se menos eficiente na contenção das perdas de água por escoamento superficial, em sistema de semeadura direta. Além da menor eficiência em conter perdas de água, no espaçamento reduzido $(0,9 \mathrm{~m})$ há também maior movimentação de solo, gasto de combustível e horas de trabalho.

Esses resultados contrastam com os obtidos por outros autores, como Nishijima \& Rigles (1987), ao avaliarem a eficiência do mulching vertical no manejo da enxurrada, em Argissolo Vermelho-Amarelo, em Santa Maria, RS; os autores concluíram que a adoção dessa técnica com espaçamento de $10 \mathrm{~m}$ entre sulcos reduziu em $52 \%$ a taxa de enxurrada. Herbes (2003), avaliando o mulching vertical em diferentes espaçamentos entre sulcos, 5 e 10 $\mathrm{m}$, sob chuva simulada, entre 70 e $106 \mathrm{~mm} \mathrm{~h}^{-1}$, durante o ciclo das culturas da soja e do trigo, concluiu que a adoção da técnica reduziu o escoamento em 48,66 e 54,54 \%, respectivamente, para os dois espaçamentos. Também Dalla Costa (2004) e Garcia \& Rigles (2008), avaliando o mulching vertical nas mesmas condições, concluíram que houve redução nas perdas de água por escoamento superficial entre 49,6 e $67,1 \%$.

Neste trabalho, as perdas foram inferiores a $1 \%$, podendo ser consideradas muito baixas. Esses resultados devem-se à distribuição irregular das precipitações no período de avaliações (Tabela 1), uma vez que a pesquisa foi conduzida em condições de campo, diferentemente daquelas dos autores supracitados, os quais utilizaram simuladores de chuva. O baixo volume de chuva precipitado, sobretudo nos meses de janeiro e fevereiro, certamente contribuiu para a redução nas perdas de água por escoamento superficial, uma vez que a intensidade, dura-

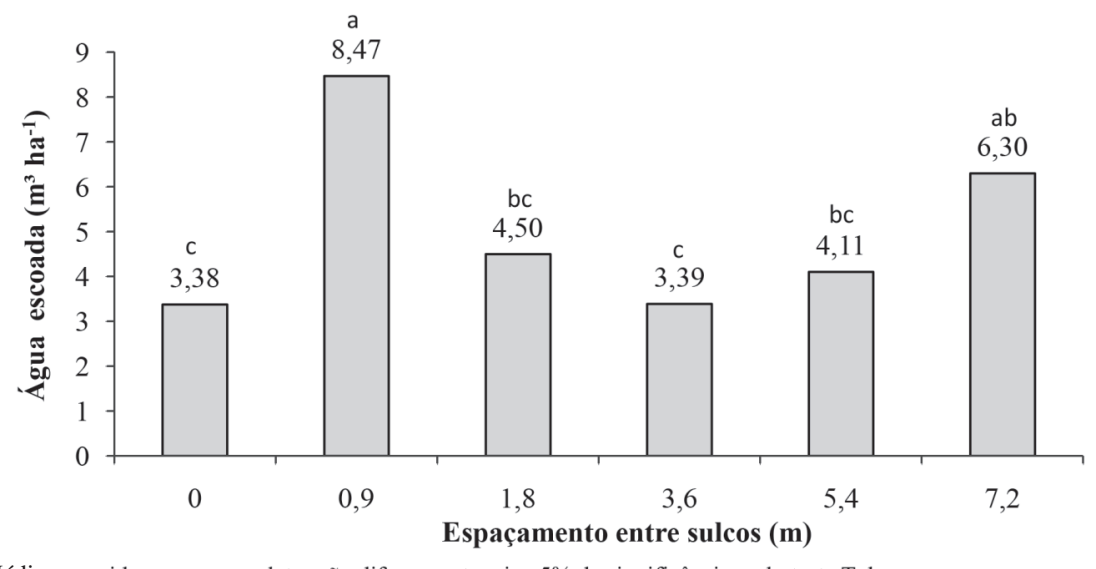

Médias seguidas por mesma letra não diferem entre si, a 5\% de significância, pelo teste Tukey.

Figura 4. Perdas de água por escoamento superficial em eventos de chuva de $50 \mathrm{~mm}$ em sistema de semeadura direta com sulcos de mulching vertical em diferentes espaçamentos.

Tabela 3. Atributos físicos e texturais do Argissolo Vermelho-Amarelo distrófico em diferentes profundidades

\begin{tabular}{|c|c|c|c|c|c|c|c|c|c|c|c|}
\hline \multirow{2}{*}{$\begin{array}{l}\text { Profundidade } \\
\mathrm{cm}\end{array}$} & \multirow{2}{*}{$\begin{array}{c}\mathbf{K}_{0} \\
\mathrm{~mm} \mathrm{~h}^{-1}\end{array}$} & \multirow{2}{*}{$\begin{array}{c}D s \\
\mathrm{~g} \mathrm{~cm}^{-3}\end{array}$} & Micro & Macro & $P t$ & $A G$ & $A F$ & silte & Argila & $A D A$ & \multirow{2}{*}{ Textura } \\
\hline & & & \multicolumn{3}{|c|}{$\mathrm{cm}^{3} \mathrm{~cm}^{-3}$} & \multicolumn{5}{|c|}{ dag kg-1 } & \\
\hline $5-10$ & 67,60 & 1,36 & 0,36 & 0,09 & 0,45 & 31 & 15 & 12 & 42 & 14 & $\mathrm{Aa}$ \\
\hline $20-25$ & 27,30 & 1,41 & 0,38 & 0,05 & 0,43 & 30 & 13 & 10 & 47 & 12 & $\mathrm{R}$ \\
\hline $40-45$ & 55,51 & 1,35 & 0,36 & 0,09 & 0,45 & 25 & 14 & 11 & 50 & 2 & $\mathrm{R}$ \\
\hline
\end{tabular}

$\mathrm{K}_{0}=$ condutividade hidráulica em meio saturado, $\mathrm{Ds}=$ densidade do solo, micro = microporosidade, macro = macroporosidade, Pt $=$ porosidade total, $\mathrm{AG}=$ areia grossa, $\mathrm{AF}=$ areia fina, $\mathrm{ADA}=$ argila dispersa em água, $\mathrm{Aa}=$ Argiloarenosa, $\mathrm{r}=\operatorname{argila}$. 
ção e frequência das chuvas são os principais fatores que interferem na ocorrência do escoamento superficial (Bertoni \& Lombardi Neto, 1990; Pires \& Souza, 2006).

Com relação às concentrações de nutrientes perdidos na água de escoamento superficial, foi possível observar que não houve diferenças significativas entre os efeitos dos diferentes tratamentos estudados (Tabela 4). Resultados semelhantes foram encontrados por Dalla Costa (2004), Garcia \& Rigles (2008), que, avaliando as perdas de nutrientes, na água de escoamento, em semeadura direta com mulching vertical, em duas distâncias, 5 e 10 m, não constataram diferenças significativas entre os tratamentos avaliados. Garcia \& Rigles (2008) ressalta que o mulching vertical, por si só, não é eficiente para controlar as perdas de nutrientes na água de escoamento superficial.

\section{B. Perdas de solo e nutrientes no sedimento}

Ao analisar os valores médios de sedimento proveniente do escoamento superficial (Figura 5), é possível observar que não houve diferença significativa, a 5\%, para a perda de solo.

Os valores de perdas de sedimentos, apresentados neste trabalho, podem ser considerados baixos, sendo inferiores aos encontrados por Dotto \& Rigles (1989), os quais, avaliando o efeito de diferentes práticas de manejo do solo nas perdas por escoamento superficial, encontraram valores médios de sedimentos escoados, para o tratamento com mulching vertical, de $22 \mathrm{~kg} \mathrm{ha}^{-1}$. Também Amaral et al. (2008), avaliando as perdas de água e de solo, por erosão hídrica pluvial, em diferentes sistemas de preparo do solo, encontraram valores próximos, com perdas de solo de 3 e $20 \mathrm{~kg} \mathrm{ha}^{-1}$ para as culturas da soja e do trigo, respectivamente, em semeadura direta. Esses autores consideraram essas quantidades baixas, para as perdas de solo, considerando o valor de tolerância calculado pela EUPS, de $5000 \mathrm{~kg} \mathrm{ha}^{-1}$.

Os teores de nutrientes perdidos nos sedimentos apresentaram comportamento semelhante aos perdidos na água de escoamento, não diferindo, significativamente, entre os diferentes tratamentos (Tabela 4). Esses resultados mostram que, tanto para as perdas de nutrientes na água, quanto nos sedimentos escoados, não foi constatado efeito dos tratamentos adotados.

\section{Perdas totais de água, solo e nutrientes}

Ao se analisarem as perdas totais de água e de solo, é possível observar que, para o período em questão, elas apresentam comportamento semelhante ao das perdas parciais, em que o tratamento com $0,9 \mathrm{~m}$ entre sulcos diferiu significativamente dos demais, exceto do tratamento com 7,2 m, que apresentou maiores perdas totais de água $\left(157,68 \mathrm{~m}^{3} \mathrm{ha}^{-1}\right)$ por escoamento superficial.

Comparando-se as perdas totais de água e de solo, é possível notar que, assim como já constatado anteriormente, elas seguiram a mesma tendência. Esse comportamento também foi constatado por Bertol et al. (2004), os quais, avaliando a erosão hídrica em diferentes sistemas de manejo do solo, também observaram que, nos trata-

Tabela 4. Concentrações de nutrientes e matéria orgânica (MO) na água e no sedimento provenientes do escoamento superficial em sistema de semeadura direta com Mulching Vertical

\begin{tabular}{|c|c|c|c|c|c|}
\hline Tratamento & MO & $\mathbf{P}$ & $\mathbf{K}^{+}$ & $\mathrm{Ca}^{2+}$ & $\mathbf{M g}^{2+}$ \\
\hline Espaço entre sulcos (m) & \multicolumn{5}{|c|}{$\mathbf{m g ~ L ^ { - 1 }}$} \\
\hline \multicolumn{6}{|c|}{ Solução } \\
\hline 0 (0 EMV) & $3,07 \mathrm{a}$ & $0,07 \mathrm{a}$ & $5,36 \mathrm{a}$ & $5,75 \mathrm{a}$ & $0,74 \mathrm{a}$ \\
\hline 0,9 (1 EMV) & $6,66 \mathrm{a}$ & $0,11 \mathrm{a}$ & $7,82 \mathrm{a}$ & $5,63 \mathrm{a}$ & $0,80 \mathrm{a}$ \\
\hline 1,8 (2 EMV) & $4,00 \mathrm{a}$ & $0,11 \mathrm{a}$ & 6,33 & $5,67 \mathrm{a}$ & $0,75 \mathrm{a}$ \\
\hline 3,6 (4 EMV) & $3,17 \mathrm{a}$ & $0,13 \mathrm{a}$ & $6,50 \mathrm{a}$ & $5,56 \mathrm{a}$ & $0,74 \mathrm{a}$ \\
\hline 5,4 (6 EMV) & $5,82 \mathrm{a}$ & $0,17 \mathrm{a}$ & $5,91 \mathrm{a}$ & $5,63 \mathrm{a}$ & $0,76 \mathrm{a}$ \\
\hline 7,2 (8 EMV) & $7,75 \mathrm{a}$ & $0,11 \mathrm{a}$ & $7,30 \mathrm{a}$ & $5,63 \mathrm{a}$ & $0,78 \mathrm{a}$ \\
\hline \multirow[t]{3}{*}{$\mathrm{CV}(\%)$} & 41,65 & 37,52 & 29,65 & 2,29 & 7,61 \\
\hline & dag kg- & \multicolumn{2}{|c|}{$\mathbf{m g ~ d m} \mathbf{m}^{-3}$} & \multicolumn{2}{|c|}{ cmolc dm ${ }^{-3}$} \\
\hline & & \multicolumn{2}{|c|}{ Sedimento } & & \\
\hline 0 (0 EVMV) & $3,47 \mathrm{a}$ & $15,70 \mathrm{a}$ & $92,00 \mathrm{a}$ & $1,85 \mathrm{a}$ & $0,54 \mathrm{a}$ \\
\hline 0,9 (1 EVMV) & $2,83 \mathrm{a}$ & $12,53 \mathrm{a}$ & $89,53 \mathrm{a}$ & $1,23 \mathrm{a}$ & $0,38 \mathrm{a}$ \\
\hline 1,8 (2 EVMV) & $3,08 \mathrm{a}$ & $18,47 \mathrm{a}$ & $86,00 \mathrm{a}$ & $1,40 \mathrm{a}$ & $0,48 \mathrm{a}$ \\
\hline 3,6 (4 EVMV) & $3,13 \mathrm{a}$ & $17,03 \mathrm{a}$ & $83,00 \mathrm{a}$ & $1,81 \mathrm{a}$ & $0,50 \mathrm{a}$ \\
\hline 5,4 (6 EVMV) & $4,27 \mathrm{a}$ & $20,90 \mathrm{a}$ & $92,33 \mathrm{a}$ & $1,94 \mathrm{a}$ & $0,60 \mathrm{a}$ \\
\hline 7,2 (8 EVMV) & $2,87 \mathrm{a}$ & $12,27 \mathrm{a}$ & $89,00 \mathrm{a}$ & $1,47 \mathrm{a}$ & $0,43 \mathrm{a}$ \\
\hline $\mathrm{CV}(\%)$ & 16,63 & 20,58 & 10,49 & 21,30 & 16,25 \\
\hline
\end{tabular}

Médias seguidas por mesma letra na coluna não diferem entre si, a 5\% de significância, pelo teste Tukey. 
mentos com semeadura direta, a perda de solo seguiu a mesma tendência da perda de água. Esse comportamento é justificado, pelos autores, em função da intensidade de chuva e do volume de água escoada, uma vez que o aumento da intensidade da chuva diminuiu a estabilidade dos agregados do solo e o aumento do volume escoado implica maior capacidade de transporte de sedimentos, em razão de sua maior energia.

Os valores apresentados na Tabela 2 não se referem à quantidade disponível dos elementos, por hectare de camada arável ( 0 a $20 \mathrm{~cm}$ de profundidade), mas, às quantidades de cada elemento perdidas na água e no solo escoados, em um hectare.

Ao analisar as perdas totais de nutrientes e de MO na água de escoamento superficial, é possível constatar que, diferentemente das perdas parciais nas precipitações de $50 \mathrm{~mm}$, foram constatadas diferenças significativas entre o efeito de tratamentos para todos os atributos avaliados. Esses resultados mostram que o aumento do volume de água escoado interfere diretamente no comportamento dos tratamentos, quanto à eficiência em conter perdas de nutrientes e de MO por escoamento superficial.

Entre os atributos avaliados, o teor de potássio foi o que apresentou as maiores quantidades perdidas na água de escoamento, seguido pelos de cálcio, matéria orgânica, magnésio e fósforo. Segundo Volk et al. (2004), as perdas de nutrientes têm relação direta com sua concentração no solo de origem e no resíduo da superfície. A maior quantidade de potássio perdida, em relação à do fósforo, deve-se à menor adsorção do potássio às cargas negativas do solo, e, consequentemente, maior mobilidade desse elemento, fazendo com que seu movimento seja por fluxo de massa. O fósforo, por sua vez, é fortemente retido pelas cargas positivas dos óxidos de $\mathrm{Fe}$ e $\mathrm{Al}$ da fração argila, o que faz com que seu movimento seja mais lento no solo, ocorrendo por difusão, e consequentemente, haja menores perdas desse elemento por escoamento superficial (Bertol et al., 2004).
Também deve ser considerado o efeito da adubação, uma vez que a área do estudo apresenta um histórico de cultivo com culturas anuais, sobretudo milho e feijão. Segundo Schick et al. (2000), a aplicação de adubos por um tempo prolongado tende a aumentar a concentração de P e K na superfície do solo, especialmente na semeadura direta, proporcionando aumento das concentrações desses nutrientes, tanto na água, quanto nos sedimentos presentes no escoamento superficial.

Ao avaliar o efeito dos tratamentos quanto às perdas totais de nutrientes, é possível constatar que, de maneira geral, o tratamento com $0,9 \mathrm{~m}$ entre sulcos diferiu dos demais, apresentando as maiores perdas. Essas perdas mais elevadas, quando comparadas com as dos demais tratamentos, estão diretamente relacionadas com as maiores perdas de água apresentadas por esse tratamento.

As quantidades totais de nutrientes perdidos nos sedimentos, por escoamento superficial (Tabela 2), assim como as perdas totais da água de escoamento, foram estimadas em função da quantidade total de solo perdido no período 2009/10.

Ao analisar essas perdas, observam-se diferenças significativas quanto ao efeito de tratamentos, para teores de fósforo, potássio e matéria orgânica (MO), não sendo constatadas diferenças para os de cálcio e magnésio. A matéria orgânica foi o atributo que apresentou as maiores quantidades perdidas, seguida pelo potássio, cálcio, magnésio e fósforo. Esses resultados mostram que o escoamento superficial remove a camada do solo mais rica em matéria orgânica. Este fato apresenta grande relevância ambiental, uma vez que, segundo McGregor et al. (1996), a perda de matéria orgânica por erosão tem grande importância para os processos de eutrofização de mananciais, colocando em perigo a vida aquática.

Ao se compararem as perdas totais de nutrientes $\left(\mathrm{P}, \mathrm{K}^{+}\right.$, $\mathrm{Ca}^{2+}$ e $\mathrm{Mg}^{2+}$ ) nos sedimentos e na água de escoamento superficial, é possível constatar que as maiores quantidades são perdidas na água de escoamento, mostrando que

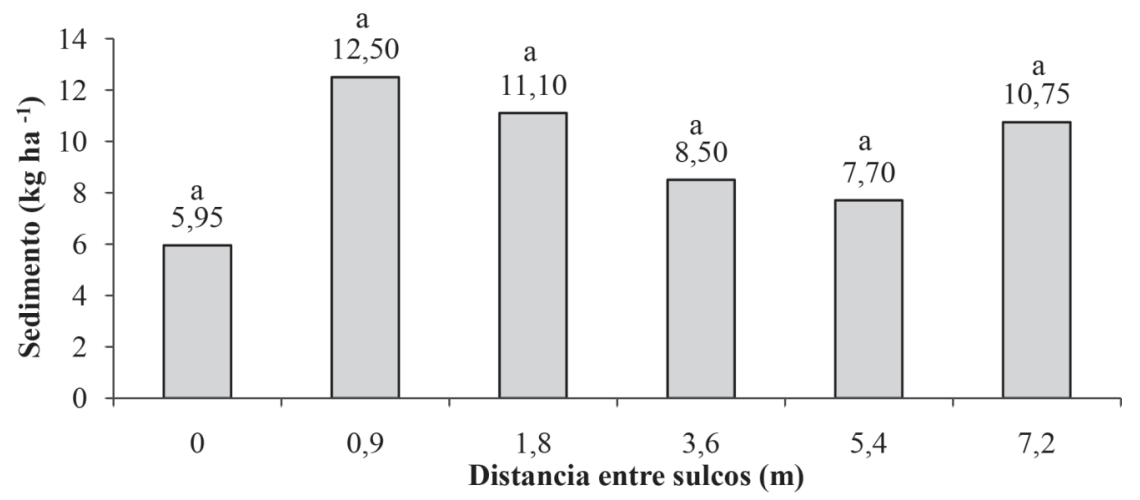

Médias seguidas por mesma letra não diferem entre si, a 5\% de significância ,pelo teste Tukey.

Figura 5. Perdas de solo por escoamento superficial em eventos de chuva de $50 \mathrm{~mm}$ em sistema de semeadura direta com sulcos de Mulching Vertical em diversos espaçamentos. 
apesar de inicialmente não terem sido constatadas diferenças expressivas entre as duas formas, quando são computadas as perdas totais desses elementos, as perdas na água de escoamento mostram-se bem mais relevantes.

Esses resultados podem ser atribuídos ao fato de que o volume de água escoada é superior à quantidade de solo perdido, justificando, desta forma, as maiores quantidades de nutrientes perdidos por escoamento superficial. Resultados semelhantes são apresentados por Hernani et al. (1999), os quais, avaliando perdas por erosão hídrica de $\mathrm{Ca}^{2+}, \mathrm{Mg}^{2+}, \mathrm{K}^{+}$(trocáveis e solúveis) e $\mathrm{P}$ disponível, tanto no sedimento, quanto em solução, encontraram maiores valores desses elementos em solução, quando comparados com os dos sedimentos, para o sistema de semeadura direta.

Com relação ao efeito de tratamentos, observam-se, de modo geral, diferenças significativas entre os tratamentos com 0 e 0,9 m entre sulcos para fósforo, potássio e matéria orgânica, sendo que o primeiro apresentou as menores quantidades perdidas desses atributos. Esses resultados evidenciam que a movimentação excessiva do solo promovida pelo tratamento com $0,9 \mathrm{~m}$ entre sulcos, durante a implantação da técnica, potencializa as perdas de água, solo e nutrientes, tanto nos sedimentos, quanto na água de escoamento superficial, reduzindo o efeito da cobertura morta nesse sistema de cultivo.

\section{CONCLUSÕES}

Pela metodologia proposta e nas condições avaliadas, o mulching vertical não se mostrou eficiente em conter as perdas de água, de solo e de nutrientes (na água e nos sedimentos) por escoamento superficial.

O aumento do volume de água escoado interfere diretamente no comportamento dos tratamentos, quanto à eficiência em conter perdas de nutrientes e de MO por escoamento superficial.

\section{AGRADECIMENTOS}

À Fundação Arthur Bernardes, pelo apoio financeiro ao desenvolvimento do projeto; à CAPES e ao CNPq, pela concessão da bolsa de estudos.

\section{REFERÊNCIAS}

Alves AGC, Cogo NP \& Levien R (1995) Relações da erosão do solo com a persistência da cobertura vegetal morta. Revista Brasileira de Ciência do Solo, 19:127-132.

Amaral AJ, Bertol I, Cogo N P \& Barbosa FT (2008) Redução da erosão hídrica em três sistemas de manejo do solo em um Cambissolo Húmico da Região do Planalto Sul - Catarinense. Revista Brasileira de Ciência do Solo, 32:2145-2155.

Anschütz J, Kome A, Nederlof M, Neef R \& Ven TV (2005) Recolha de água e retenção de umidade do solo. $1^{\mathrm{a}}$ ed. Fundação Agromisa, Wageningen. 110p.
Bertol I, Cogo NP \& Levien R (1989) Cobertura morta e métodos de preparo do solo na erosão hídrica em solo com crosta. Revista Brasileira de Ciência do Solo, 13:373-379.

Bertol I, Cogo NP \& Levien R (1997) Erosão hídrica em diferentes preparos do solo logo após as colheitas de milho e trigo, na presença e ausência dos resíduos culturais. Revista Brasileira de Ciência do Solo, 21:409-418.

Bertol I, Guadagnin JC, Cassol PC, Amaral AJ \& Barbosa FT (2004) Perdas de fósforo e potássio por erosão hídrica em um Inceptisol sob chuva natural. Revista Brasileira de Ciência do Solo, 28:485494.

Bertoni J \& Lombardi Neto F (1990) Conservação do solo. 3, ed. São Paulo, Ícone. 355p.

Castro LG, Cogo NP, Volk LBS (2006) Alterações na rugosidade superficial do solo pelo preparo e pela chuva e sua relação com a erosão hídrica. Revista Brasileira de Ciência do Solo, 30:339352.

Cogo NP (1981) Effect of residue cover, tillage induced-roughness, and slope lenght on erosion and related parameters. Doctoral Thesis. Purdue University, West Lafayette. 346p.

Cogo NP, Levien R \& Schwarz RA (2003) Perdas de solo e água por erosão hídrica influenciadas por método de preparo, classes de declive e níveis de fertilidade do solo. Revista Brasileira de Ciência do Solo, 27:743-753.

Dalla Costa DR (2004) Nutrientes na água de escoamento superficial em plantio direto com mulching vertical. Dissertação de Mestrado. Universidade Federal de Santa Maria, Santa Maria. 79 p.

Denardin JE, Kochhann RA \& Righes AA (2005) Mulching Vertical: técnica de manejo de enxurradas em Sistema Plantio Direto. Disponível em: <http://www.plantiodireto.com.br/ ?body=cont_int\&id=611>. Acessado em: 16 de abril de 2013.

Dotto JMR \& Rigles AA (1989) Efeitos do manejo do solo nas perdas por erosão. Revista Centro de Ciências Rurais, 19:1930 .

Empresa Brasileira de Pesquisa Agropecuária - Embrapa. Centro Nacional e Pesquisa em Solos (2006) Sistema Brasileiro de Classificação de Solos. Brasilia, Embrapa-Solos. 306p.

Garcia SM \& Rigles AA (2008) Vertical mulching e manejo da água em Semeadura direta. Revista Brasileira de Ciência do Solo, 32:833-842.

Herbes MG (2003) Escoamento superficial em sistema de plantio direto com mulching vertical. Dissertação de Mestrado. Universidade Federal de Santa Maria, Santa Maria. 107p.

Hernani LC, Kurihara CH \& Silva WM (1999) Sistemas de manejo de solo e perdas de nutrientes e matéria orgânica por erosão. Revista Brasileira de Ciência do Solo, 23:145-154.

Klein VA, Anesi AL \& Barbosa R (2000) Mulching vertical reduz a enxurrada em área sob plantio direto. In: Reunião Brasileira de Ciência do Solo, Pelotas. Anais, p.147-154. CD-ROM.

McGregor KC (1996) USDA and MAFES: cooperative soil conservation studies at Holly Springs - 1956-1996. Mississipi State, MAFES. 21p. (Bulletin, 1044)

Morin J \& Van Winkel J (1996) The effect of raindrop impact and sheet erosion on infiltration rate and crust formation. Soil Science Society of America Journal, 60:1223-1227.

Nishijima T \& Rigles AA (1987) Escoamento superficial de água em cinco sistemas de manejo do solo com cultura de milho. Revista Centro de Ciências Rurais, 17:223-233.

Pires FR \& Souza CM (2006) Práticas mecânicas de conservação do solo e da água. $2^{\mathrm{a}}$ ed. Viçosa, UFV. 216p. 
Reichert JM, Suzuki LEAS \& Reinert DJ (2007) Compactação do solo em sistemas agropecuários e florestais: identificação, efeitos, limites críticos e mitigação. Tópicos Ci. Solo. Santa Maria, UFSM. $134 \mathrm{p}$.

SAEG Sistema para Análises Estatísticas (2007) Versão 9.1. Fundação Arthur Bernardes, UFV, Viçosa. CD-ROM.

Schaefer CER, Silva DD, Paiva KWN, Pruski FF, Filho MRA \& Albuquerque MA (2002) Perda de solo, nutrientes, matéria orgânica e efeitos microestruturais em Argissolo Vermelho-Amarelo sob chuva simulada. Pesquisa Agropecuária Brasileira, Brasília, 37:669-678.
Schick J, Bertol I, Balbinot Jr Aa \& Batistela O (2000) Erosão hídrica em Cambissolo Húmico alumínico submetido a diferentes sistemas de preparo e cultivo do solo: II. Perdas de nutrientes e carbono orgânico. Revista Brasileira de Ciência do Solo, 24:437-447.

Tedesco MJ, Gianello C, Bissani CA, Bohnen H \& Volkweiss SJ (1995) Análise de solos, plantas e outros materiais. 2a ed. Porto Alegre, UFRGS. 174p.

Volk LBS, Cogo NP, Portz G \& Rech JPD (2004) Perda de nutrientes por erosão hídrica em solo com e sem cultivo, na condição de semeadura direta. In: $15^{\circ}$ Reunião Brasileira de Manejo e Conservação do Solo e Água. Manejo integrado à ciência do solo na produção de alimentos. Anais, Santa Mara. CD-ROM. 